This item was submitted to Loughborough's Research Repository by the author.

Items in Figshare are protected by copyright, with all rights reserved, unless otherwise indicated.

\title{
Lightly loaded lubricated impacts: idle gear rattle
}

PLEASE CITE THE PUBLISHED VERSION

http://dx.doi.org/10.1016/j.jsv.2007.03.077

PUBLISHER

(c) Elsevier

VERSION

AM (Accepted Manuscript)

PUBLISHER STATEMENT

This work is made available according to the conditions of the Creative Commons Attribution-NonCommercialNoDerivatives 4.0 International (CC BY-NC-ND 4.0) licence. Full details of this licence are available at: https://creativecommons.org/licenses/by-nc-nd/4.0/

\section{LICENCE}

CC BY-NC-ND 4.0

\section{REPOSITORY RECORD}

Tangasawi, Osman A.M., Stephanos Theodossiades, and Homer Rahnejat. 2019. "Lightly Loaded Lubricated Impacts: Idle Gear Rattle". figshare. https://hdl.handle.net/2134/18656. 


\title{
Lightly Loaded Lubricated Impacts: Idle Gear Rattle
}

\author{
O. Tangasawi, S. Theodossiades ${ }^{*}$ and H. Rahnejat
}

\begin{abstract}
Wolfson School of Mechanical \& Manufacturing Engineering, Loughborough University, LE11 3TU, Loughborough, UK
\end{abstract}

PAGES: 32

FIGURES: 7

* Corresponding author. Tel: +44 1509 227664; Fax: +44 1509 227648;

e-mail: S.Theodossiades@lboro.ac.uk 


\section{ABSTRACT}

Idle gear rattle is associated with the characteristic noise that unselected impacting gears radiate to the environment. It is induced by engine order vibration in the presence of backlash in the unengaged gear pairs, resulting in oscillatory response within their backlash range. A tribo-dynamic model of a front wheel drive manual transmission has been developed to study idle rattle, considering the hydrodynamic contact film reaction and flank friction. The model includes the torsional motions of the idle gears and the lateral motions of the supporting output shafts. The hydrodynamic lubricant film formed between the gear teeth under light impact loads behaves as a non-linear spring-damper mechanism, whilst the inclusion of the shafts' bearing compliances introduces additional non-linear terms, which are modelled as piecewise linear functions. The aim of the paper is to demonstrate the effect of the lubricant on the system's response, which is eventually transferred to the gearbox case through the bearings. The results are found to conform closely to experimental measurements taken from a vehicle equipped with a manual transmission of the same type.

\section{KEYWORDS}

Transmission idle gear rattle, hydrodynamic regime of lubrication, lubricant stiffness.

\section{NOTATION}

C Clearance between gear and shaft.

$C_{b} \quad$ Gear teeth normal backlash.

F $\quad$ Petroff friction force. 
$F_{f} \quad$ Hydrodynamic flank friction force.

$F_{i(i=1 \ldots, \ldots, \text { rev })} \quad$ Hydrodynamic load on the $i^{\text {th }}$ tooth flank

$h \quad$ Lubricant film thickness.

$I_{i(i=1,2,3,4,5,6)} \quad$ Moment of inertia of the $i^{\text {th }}$ gear wheel.

$I_{\text {prev }} \quad$ Moment of inertia of reverse pinion

$I_{\text {wrev }} \quad$ Moment of inertia of reverse gear wheel

K Linear stiffness.

$K_{0} \quad$ Mean lubricant stiffness.

$K_{\text {oi }(i=1, \ldots, 6)} \quad$ Mean lubricant stiffness of the $i^{\text {th }}$ gear pair.

$K_{o(\text { rev })} \quad$ Mean lubricant stiffness of reverse gear pair.

$K_{c p} \quad$ Amplitude of the alternating lubricant component (the $p^{\text {th }}$ cosine term).

$K_{s p} \quad$ Amplitude of the alternating lubricant component (the $p^{\text {th }}$ sine term).

$L \quad$ Length of contact line

l The distance between the instantaneous contact point and the pitch point.

$l_{1} \quad$ Length of contact surface in the conformal contact between gear and shaft

$n_{i} \quad$ The tooth number of the $i^{\text {th }}$ gear wheel.

$r_{b} \quad$ Base radius.

$r_{c} \quad$ Radial distance of pinion and wheel contact point

$r_{e q} \quad$ The equivalent curvature radius of two teeth surfaces at their contact point taken at the normal plane. 


$$
\begin{aligned}
& r_{\text {os }} \quad \text { Radius of the output shaft } \\
& r_{p} \quad \text { Contact radius of the pinion. } \\
& r_{p p} \quad \text { Pitch radius of the pinion. } \\
& r_{\text {prev }} \quad \text { Contact radius of the reverse speed pinion } \\
& r_{w w} \quad \text { Pitch radius of the gear wheel. } \\
& r_{\text {wi }(i=1 \ldots 6, \text { rev })} \quad \text { Contact radius of the } i^{\text {th }} \text { gear wheel. } \\
& T_{\text {fwi }(i=1 \ldots, \text {, rev })} \quad \text { Flank friction torque on the } i^{\text {th }} \text { gear wheel. } \\
& T_{\text {tractwi (i=1..., rev) }} \text { Tractive torque between the output shaft and the } i^{\text {th }} \text { gear wheel } \\
& u \quad \text { Entraining speed of gear teeth during meshing action } \\
& u_{s} \quad \text { Sliding velocity of the meshing gear teeth surfaces } \\
& v \quad \text { Tangential velocity between idle gear and supporting shaft } \\
& v_{w} \quad \text { Rolling velocity of the gear wheel tooth surface. } \\
& v_{p} \quad \text { Rolling velocity of the pinion tooth surface. } \\
& v_{\text {pitch }, p} \quad \text { Pitch velocity of the pinion. } \\
& v_{\text {pitch,w }} \quad \text { Pitch velocity of the gear wheel. } \\
& \text { W Lubricant hydrodynamic reaction. } \\
& x_{1} \quad \text { Displacement of the first output shaft along the } x_{1} \text {-axis. } \\
& y_{1} \quad \text { Displacement of the first output shaft along the } y_{1} \text {-axis } \\
& x_{2} \quad \text { Displacement of the first output shaft along the } x_{2} \text {-axis } \\
& y_{2} \quad \text { Displacement of the first output shaft along the } y_{2} \text {-axis }
\end{aligned}
$$



$\alpha_{n} \quad$ Normal pressure angle.
$\alpha_{t} \quad$ Transverse pressure angle.
$\beta \quad$ Pitch circle helix angle.
$\beta_{b} \quad$ Base circle helix angle.
$\Delta \quad$ Contact lines inclination angle.
$\Delta t \quad$ Time step.
$\eta_{0} \quad$ Dynamic viscosity at atmospheric conditions.

$\Lambda \quad$ Bearing reaction.

$\rho_{p} \quad$ Curvature radius of the pinion tooth surface in the transverse plane.

$\rho_{\text {wi }} \quad$ Curvature radius of the $i^{\text {th }}$ gear wheel tooth surface in the transverse plane.

$\varphi_{1, \text { prev }} \quad$ Angular displacement of the $1^{\text {st }}$ speed gear and reverse pinion

$\varphi_{i(i=2 \ldots 6)} \quad$ Angular displacement of $2^{\text {nd }}, 3^{\text {rd }}, 4^{\text {th }}, 5^{\text {th }}$ and $6^{\text {th }}$ idle gear wheels

$\varphi_{\text {in }} \quad$ Angular displacement of the input shaft

$\varphi_{\text {wrev }} \quad$ Angular displacement of the reverse speed gear

$\varphi_{p}, \varphi_{w} \quad$ Pinion and gear angular displacements

$\dot{\varphi}_{\text {os }} \quad$ Output shaft rotational speed, here $\dot{\varphi}_{\text {os }}=0$

$\dot{\varphi}_{w} \quad$ Idle gear wheel angular velocity.

\section{Subscripts}

$a, b, c, d \quad$ Bearing designations on the output shafts.

p Pinion 
prev $\quad$ Pinion of reverse gear

w Gear wheel

wrev Wheel of reverse gear

$x, y \quad$ In the $\mathrm{x}$ - and $\mathrm{y}$ - directions respectively.

$x 1, y 1, x 2, y 2$ Related to the $x_{1}, y_{1}, x_{2}, y_{2}$ axes respectively.

xji Related to the $x_{j}$ axis and $i^{\text {th }} \operatorname{gear}(j=1,2)$.

xjin Related to the $x_{j}$ axis and input $\operatorname{shaft}(j=1,2)$.

xjrev $\quad$ Related to the $x_{j}$ axis and reverse gear $(j=1,2)$.

xjyk $\quad$ Related to the $x_{j}$ axis and $y_{k}$ displacement $(j=1,2 ; k=1,2)$.

xjxk Related to the $x_{j}$ axis and $x_{k}$ displacement $(j=1,2 ; k=1,2)$.

yji Related to the $y_{j}$ axis and $i^{\text {th }} \operatorname{gear}(j=1,2)$.

yjin $\quad$ Related to the $y_{j}$ axis and input $\operatorname{shaft}(j=1,2)$.

yjrev $\quad$ Related to the $y_{j}$ axis and reverse $\operatorname{gear}(j=1,2)$.

yjxk Related to the $y_{j}$ axis and $x_{k}$ displacement $(j=1,2 ; k=1,2)$.

yjyk $\quad$ Related to the $y_{j}$ axis and $y_{k} \operatorname{displacement}(j=1,2 ; k=1,2)$.

\section{INTRODUCTION}

Gear rattle is caused by torsional vibrations of the crankshaft due to the engine firing frequency and inertial imbalance (Dogan and Lechner [1], Shih et al [2]). This initiates cyclic angular accelerations to be transmitted from the engine to the transmission input shaft, leading to impacts of gear and spline teeth due to gear teeth oscillating within their 
backlash (Dogan and Lechner [1], Seaman et al [3], Padmanabhan et al [4]). The gear vibrations are transmitted via the supporting bearings to the transmission case (Fujimoto and Kizuka [5]), which vibrates as a membrane, hence, acting as a sound radiator (Sakai et al [6], Wang et al [7]) to the environment. In most of the literature available, torsional models of the idle gears are presented to simulate gear rattle, including hysteresis, gear backlash, the meshing stiffness and linear damping. Backlash is usually modelled using the dead space function, while the clutch stiffness and hysteresis have been modelled as piecewise linear functions (Singh et al [8], Kim and Singh [9]). Fujimoto and Kizuka [5] used a temperature-dependent drag torque.

The gear teeth stiffness has been usually considered as constant (Sakai et al [6], Kamo et al [10]) or using time-varying coefficients (Wang et al [11], Yakoub et al [12], Kahraman and Singh [13], Blankenship and Singh [14] and Theodossiades and Natsiavas [15, 16]). The contact stiffness utilised by Yakoub et al [12] was also dependent on gear geometry, whilst Bellomo et al [17] represented the teeth contact forces following the Hertzian approach and considering coefficients of restitution. Brancati et al [18] modelled the gear stiffness, using an approximate equation, in which the stiffness depends on the position of the pinion in the contact zone, tooth width, tooth depth and helix angle. Similar approach was also followed by Umezawa et al [19] and Cai [20], who modified the approximate method by incorporating the effects of tooth numbers and addendum modifications. Furthermore, Brancati et al [18] followed Umezawa et al [19] and Cai [20] into transforming the torsional gear system into a translational system along the line of action.

Usually, lubricant effects were regarded as resistive action only, and mostly dry gear teeth impacts have been considered in rattle investigations. Rust et al [21] reported 
lubricant viscosity and oil depth as major components contributing to drag torque. Dogan [22] considered the oil squeeze action between the meshing teeth and the gear flow action in the bulk oil as resistive torques. Examining the oil effect further, Gnanakumarr et al [23] assumed line contact between the gear flanks and hydrodynamic action in the lightly loaded counter-formal lubricated contacts between the gear teeth. A hydrodynamic formula proposed by Rahnejat [24] was used in this investigation, which takes both forcing and damping effects into consideration and depends on the lubricant entrainment speed, the contact geometry, and the approach velocity between the teeth. Brancati et al [18] have considered the damping effects of oil only assuming an elastic force when gear teeth are in contact and non-linear damping force during separation. Unlike Gnanakumarr et al [23], who assumed the drag in idler gears to be a function of the relative velocity between gear and shaft, Brancati et al [18] considered a constant drag torque. The damping force introduced was based on assumptions, such as: constant radii of curvature (taken at the pitch points) and viscosity, and ignoring sliding velocity. Similar assumptions were used by Gnanakumarr et al [23]. In both investigations, it was concluded that the presence of lubricant in the contact zone and increased viscosity lead to reduction in rattle vibrations.

\section{THE MECHANICAL MODEL}

The mechanical model is comprised of 11 degrees of freedom (figure 1), seven of which are torsional, representing the idle gears angular motion, whilst the remaining four degrees of freedom represent the rectilinear motions of the supporting output shafts (excluding the 
axial motion). The equations of motion for the idle gears mounted on the two output shafts are then formulated as follows:

For the $1^{\text {st }}$ idle gear wheel (combined with the reverse speed pinion, as shown in figure 1)

$$
\begin{aligned}
\left(I_{1}+I_{\text {prev }}\right) \ddot{\varphi}_{1, \text { prev }}= & F_{1}\left(\varphi_{1, \text { prev }}, \varphi_{\text {in }}, \dot{\varphi}_{1, \text { prev }}, \dot{\varphi}_{\text {in }}, y_{1}\right) r_{w 1} \\
& -F_{\text {rev }}\left(\varphi_{\text {wrev }}, \varphi_{1, \text { prev }}, \dot{\varphi}_{\text {wrev }}, \dot{\varphi}_{1, \text { prev }}, y_{1}, y_{2}\right) r_{\text {prev }} \\
& -T_{f w 1}\left(\varphi_{1, \text { prev }}, \varphi_{\text {in }}, \dot{\varphi}_{1, \text { prev }}, \dot{\varphi}_{\text {in }}\right)-T_{\text {tractw1 } 1}\left(\dot{\varphi}_{1, \text { prev }}\right)
\end{aligned}
$$

For the $2^{\text {nd }}$ idle gear wheel

$$
I_{2} \ddot{\varphi}_{2}=F_{2}\left(\varphi_{2}, \varphi_{i n}, \dot{\varphi}_{2}, \dot{\varphi}_{i n}, y_{1}\right) r_{w 2}-T_{f w 2}\left(\varphi_{2}, \varphi_{i n}, \dot{\varphi}_{2}, \dot{\varphi}_{i n}\right)-T_{\text {tractw2 }}\left(\dot{\varphi}_{2}\right)
$$

For the $3^{\text {rd }}$ idle gear wheel

$$
I_{3} \ddot{\varphi}_{3}=F_{3}\left(\varphi_{3}, \varphi_{i n}, \dot{\varphi}_{3}, \dot{\varphi}_{i n}, y_{1}\right) r_{w 3}-T_{f w 3}\left(\varphi_{3}, \varphi_{i n}, \dot{\varphi}_{3}, \dot{\varphi}_{\text {in }}\right)-T_{\text {tractw3 }}\left(\dot{\varphi}_{3}\right)
$$

For the $4^{\text {th }}$ idle gear wheel

$$
I_{4} \ddot{\varphi}_{4}=F_{4}\left(\varphi_{4}, \varphi_{i n}, \dot{\varphi}_{4}, \dot{\varphi}_{i n}, y_{1}\right) r_{w 4}-T_{f w 4}\left(\varphi_{4}, \varphi_{i n}, \dot{\varphi}_{4}, \dot{\varphi}_{i n}\right)-T_{\text {tractw4 }}\left(\dot{\varphi}_{4}\right)
$$

For the $5^{\text {th }}$ idle gear wheel

$$
I_{5} \ddot{\varphi}_{5}=F_{5}\left(\varphi_{5}, \varphi_{i n}, \dot{\varphi}_{5}, \dot{\varphi}_{i n}, y_{2}\right) r_{w 5}-T_{f w 5}\left(\varphi_{5}, \varphi_{i n}, \dot{\varphi}_{5}, \dot{\varphi}_{\text {in }}\right)-T_{\text {tractw5 }}\left(\dot{\varphi}_{5}\right)
$$

For the $6^{\text {th }}$ idle gear wheel

$$
I_{6} \ddot{\varphi}_{6}=F_{6}\left(\varphi_{6}, \varphi_{i n}, \dot{\varphi}_{6}, \dot{\varphi}_{i n}, y_{2}\right) r_{w 6}-T_{f w 6}\left(\varphi_{6}, \varphi_{i n}, \dot{\varphi}_{6}, \dot{\varphi}_{i n}\right)-T_{\text {tractw6 }}\left(\dot{\varphi}_{6}\right)
$$

And for the reverse gear idle wheel

$$
\begin{aligned}
I_{\text {wrev }} \ddot{\varphi}_{\text {wrev }}= & F_{\text {rev }}\left(\varphi_{\text {wrev }}, \varphi_{1, \text { prev }}, \dot{\varphi}_{\text {wrev }}, \dot{\varphi}_{1, \text { prev }}, y_{1}, y_{2}\right) r_{\text {wrev }} \\
& -T_{\text {furev }}\left(\varphi_{\text {wrev }}, \varphi_{1, \text { prev }}, \dot{\varphi}_{\text {wrev }}, \dot{\varphi}_{1, \text { prev }}\right)-T_{\text {tractwrev }}\left(\dot{\varphi}_{\text {wrev }}\right)
\end{aligned}
$$

In the above equations, $F_{i(i=1 \ldots, \ldots, r e v)}$ represent the hydrodynamic reactions between the gear teeth meshing surfaces, $r_{\text {wi }(i=1 . \ldots, \text { rev })}$ are the contact radii of gear wheels and $r_{\text {prev }}$ is the contact radius for the reverse speed pinion. The flank friction force is given by 
$T_{\text {fwi }(i=1 . .6, \text { rev })}$, while the tractive force between the output shafts and the idle gear wheels is given by $T_{\text {tractwi }(i=1 \ldots, \ldots, \text { rev })}$.

The rectilinear equations of motions are formulated as follows (figure 1):

For the $1^{\text {st }}$ output shaft

$M_{1} \ddot{x}_{1}=F_{x 1}\left(\varphi_{i n}, \dot{\varphi}_{i n}, \varphi_{i}, \dot{\varphi}_{i}, y_{1}, y_{2}\right)-\Lambda_{a x}\left(x_{1}\right)-\Lambda_{b x}\left(x_{1}\right)$

$M_{1} \ddot{y}_{1}=F_{y 1}\left(\varphi_{i n}, \dot{\varphi}_{i n}, \varphi_{i}, \dot{\varphi}_{i}, y_{1}, y_{2}\right)-\Lambda_{a y}\left(y_{1}\right)-\Lambda_{b y}\left(y_{1}\right)$

where $i=1$, prev;2;3;4; wrev .

For the $2^{\text {nd }}$ output shaft

$M_{2} \ddot{x}_{2}=F_{x 2}\left(\varphi_{i n}, \dot{\varphi}_{i n}, \varphi_{i}, \dot{\varphi}_{i}, y_{1}, y_{2}\right)-\Lambda_{c x}\left(x_{2}\right)-\Lambda_{d x}\left(x_{2}\right)$

$M_{2} \ddot{y}_{2}=F_{y 2}\left(\varphi_{i n}, \dot{\varphi}_{i n}, \varphi_{i}, \dot{\varphi}_{i}, y_{1}, y_{2}\right)-\Lambda_{c y}\left(y_{2}\right)-\Lambda_{d y}\left(y_{2}\right)$

where $i=1$, prev;5;6; wrev

$F_{x 1}, F_{y 1}, F_{x 2}$ and $F_{y 2}$ are the sums of the components of $F_{i(i=1 \ldots, \ldots, \text { rev })}$ in the $x_{1}, y_{1}, x_{2}, y_{2}$ directions, respectively. $\Lambda_{a x}, \Lambda_{b x}, \Lambda_{a y}, \Lambda_{b y}, \Lambda_{c x}, \Lambda_{d x}, \Lambda_{c y}$ and $\Lambda_{d y}$ are the bearing reactions in $x$ and $y$ directions. The displacements of the first and second output shafts in $x$ and $y$ directions are $x_{1}, x_{2}, y_{1}$, and $y_{2}$, respectively.

Due to the low loads experienced under engine idle conditions, iso-viscous rigid hydrodynamic conditions have been assumed between the gear meshing teeth (Theodossiades et al [25]). The lubricant reaction, $W$, for such conjunctions was derived by Rahnejat [24] and also independently by Sasaki et al [26]: 
$\left.\begin{array}{ll}W=\frac{L \eta_{0} r_{e q}}{h}\left(2 u-\frac{3 \pi}{\sqrt{\frac{2 h}{r_{e q}}}} \frac{\partial h}{\partial t}\right), & \frac{\partial h}{\partial t}<0 \\ W=\frac{L \eta_{0} r_{e q}}{h}(2 u), & \frac{\partial h}{\partial t} \geq 0\end{array}\right\}$

The load on each tooth flank is then given by:

$F_{i(i=1 \ldots 6, r e v)}=W \cos \beta \cos \alpha_{n}$

The hydrodynamic flank friction (Gohar [27]) is acting normal to the line of contact (figure 2):

$F_{f}=\frac{\pi \eta_{0} u_{s} \sqrt{r_{e q}}}{\sqrt{2 h}}$

And the corresponding torque due to tooth flank friction is defined as:

$T_{f}=\frac{r_{c} F_{f} \sin \alpha_{n} \sin \beta}{\cos \beta / \cos \beta_{b}}$

The traction induced by the supporting needle bearings of the idle gears can be reasonably approximated using the hydrodynamic Petrov friction approach (Gnanakumarr et al [23]) for a concentric arrangement with zero eccentricity (figure 3), since the loads experienced under idling conditions are low. It can be written in the following form:

$F=\frac{\pi \eta_{0} v l_{1} r_{o s}}{C}$

The generated resistive torque is calculated as:

$T_{\text {tract }}=F r_{o s}$

The bearing reaction forces are in the following form (Harris [28]):

$$
\Lambda=K(x-b)^{1.11}
$$


where $x$ is the shaft displacement and $b$ is the bearing clearance. The coefficient of stiffness $K$ depends on the bearing geometric properties (Harris [28]).

\section{EXPERIMENTAL SET-UP}

A passenger vehicle equipped with a diesel engine and a manual transmission was used to validate the numerical model. The vehicle was tested with the engine in idle conditions and the transmission in neutral, in a semi-anechoic environment to minimise the influence of background noise. The aim was to correlate the frequency spectra of the numerical model output shafts to that of the transmission walls at the corresponding locations (due to limited access to the transmission shafts) and thus, to examine the model accuracy, since it is well established that rattle noise is radiated to the environment due to vibration of the gearbox surface. The mounting positions for the accelerometers were chosen in a suitable way to follow the path of vibration transfer. Thus, measurements were taken from the bearing locations on the transmission housing, the transmission wall, as well as from the transmission mounts to the vehicle chassis (figure 4). The sample rate was set to 12,000 Hz. Additionally, impact hammer testing of the gearbox housing revealed its natural frequencies.

\section{RESULTS AND DISCUSSION}

The case examined corresponds to typical values for gear backlash (from 80 to $150 \mu \mathrm{m}$, with the larger values corresponding to the higher inertia gear pairs), lubricant dynamic viscosity $\left(0.05122 \mathrm{~Pa} \cdot \mathrm{s}\right.$, corresponding to $39.4^{\circ} \mathrm{C}$ temperature of the transmission bulk lubricant) and engine speed in idle (810 rpm). Similar temperature conditions had also 
been recorded experimentally in the vehicle tested and measurements were captured for comparison reasons. The equations of motion are solved numerically, using the linear acceleration method (Timoshenko et al [29]) for sufficient real time to eliminate transient phenomena, appearing at the beginning of the simulation due to the initial conditions. The geometric and meshing cycle characteristics of the idle gears are determined, which in turn are used for the computation of the reaction forces and the response of the idle gears and output shafts. The most important excitation source in the numerical model is engine order vibration, leading to torsional fluctuations of the transmission input shaft nominal angular velocity. The input shaft response has been acquired from the vehicle under investigation and is used as input to the numerical model.

Figure 5 shows the FFT spectra of the output shafts' rectilinear motions. There are high frequency contributions in both $x$ and $y$ directions, due to the bearing stiffness affecting the motion of the shafts. More specifically, the first output shaft exhibits lower frequencies (1771 and $1798 \mathrm{~Hz}$ ) compared to the second shaft (1990 and $2137 \mathrm{~Hz}$ ) because of the larger mass of the first shaft assembly. The characteristics of the shafts' vibration are important, since these components are in the path of vibration transfer from the input shaft to the transmission case. To understand better these contributions and the lubricant effect on the system dynamics, the natural frequencies of the model arising through linearization of equations (1) - (11) are calculated, since the lubricant film behaves as a nonlinear spring, following the meshing cycle variation, The equation of motion of the input shaft is also included in this process.

The lubricant stiffness is determined by differentiating Eq. (12) with respect to the film thickness, considering the rolling term only: 
$K\left(\varphi_{i}\right)=\left|\frac{\partial W_{i}}{\partial h_{i}}\right|$

This stiffness is a function of time, since it depends on the film thickness and gear contact kinematics as a function of the rolling/sliding geometry. By neglecting the toothto-tooth variations, the fundamental period of the impacting stiffness is equal to $\varphi_{i T} \equiv 2 \pi / n_{i}$, where $n_{i}$ represents the tooth number of the driving gear (Theodossiades and Natsiavas [15]). Therefore, the lubricant stiffness can be approximately expressed in a Fourier series as follows:

$K\left(\varphi_{i}\right)=K_{0 i}+\sum_{p=1}^{\infty} K_{c p} \cos \left(p n_{i} \varphi_{i}\right)+K_{s p} \sin \left(p n_{i} \varphi_{i}\right)$

The equations of motion for the linearised model are formulated as follows, neglecting the damping terms:

For the input shaft

$$
I_{\text {in }} \ddot{\varphi}_{\text {in }}+\sum_{i=1}^{4} K_{0 i} r_{p i}\left(r_{p i} \varphi_{\text {in }}-r_{w i} \varphi_{i}-y_{1}\right)+\sum_{i=5}^{6} K_{0 i} r_{p i}\left(r_{p i} \varphi_{i n}-r_{w i} \varphi_{i}-y_{2}\right)=0
$$

For the $1^{\text {st }}$ speed idle gear (combined with the reverse gear pinion)

$$
\begin{aligned}
& \left(I_{1}+I_{\text {prev }}\right) \ddot{\varphi}_{1, \text { prev }}+K_{01} r_{w 1}\left(r_{w 1} \varphi_{1, \text { prev }}+y_{1}-r_{p 1} \varphi_{\text {in }}\right)+ \\
& K_{0(\text { rev })} r_{\text {prev }}\left(r_{\text {prev }} \varphi_{1, \text { prev }}+x_{1} \sin \varepsilon_{1}+y_{1} \cos \varepsilon_{1}-r_{\text {wrev }} \varphi_{\text {wrev }}-x_{2} \sin \varepsilon_{2}+y_{2} \cos \varepsilon_{2}\right)=0
\end{aligned}
$$

For the $2^{\text {nd }}$ speed idle gear

$$
I_{2} \ddot{\varphi}_{2}+K_{02} r_{w 2}\left(r_{w 2} \varphi_{2}+y_{1}-r_{p 2} \varphi_{i n}\right)=0
$$

For the $3^{\text {rd }}$ speed idle gear

$$
I_{3} \ddot{\varphi}_{3}+K_{03} r_{w 3}\left(r_{w 3} \varphi_{3}+y_{1}-r_{p 3} \varphi_{i n}\right)=0
$$

For the $4^{\text {th }}$ speed idle gear 


$$
I_{4} \ddot{\varphi}_{4}+K_{04} r_{w 4}\left(r_{w 4} \varphi_{4}+y_{1}-r_{p 4} \varphi_{i n}\right)=0
$$

For the $5^{\text {th }}$ speed idle gear

$$
I_{5} \ddot{\varphi}_{5}+K_{05} r_{w 5}\left(r_{w 5} \varphi_{5}+y_{2}-r_{p 5} \varphi_{i n}\right)=0
$$

For the $6^{\text {th }}$ speed idle gear

$$
I_{6} \ddot{\varphi}_{6}+K_{06} r_{w 6}\left(r_{w 6} \varphi_{6}+y_{2}-r_{p 6} \varphi_{i n}\right)=0
$$

For the reverse speed idle gear

$$
\left.\begin{array}{l}
I_{\text {wrev }} \ddot{\varphi}_{\text {wrev }}+ \\
K_{\text {orev }} r_{\text {wrev }}\left(r_{\text {wrev }} \varphi_{\text {wrev }}+x_{2} \sin \varepsilon_{2}-y_{2} \cos \varepsilon_{2}-r_{\text {prev }} \varphi_{1, \text { prev }}-x_{1} \sin \varepsilon_{1}-y_{1} \cos \varepsilon_{1}\right)=0
\end{array}\right\}
$$

For the $1^{\text {st }}$ shaft

$$
\begin{aligned}
& M_{1} \ddot{x}_{1}+\sum_{i=1}^{4} K_{x 1 i} \varphi_{i}+K_{x 1 r e v} \varphi_{r e v}+K_{x 11 n} \varphi_{i n}+K_{x 1} x_{1}+K_{x 111} y_{1}=0 \\
& M_{1} \ddot{y}_{1}+\sum_{i=1}^{4} K_{y 1 i} \varphi_{i}+K_{y 1 r e v} \varphi_{r e v}+K_{y 1 i n} \varphi_{i n}+K_{y 111} x_{1}+K_{y 1} y_{1}=0
\end{aligned}
$$

For the $2^{\text {nd }}$ shaft

$$
\begin{aligned}
& M_{2} \ddot{x}_{2}+K_{x 21} \varphi_{1}+\sum_{i=5}^{6} K_{x 2 i} \varphi_{i}+K_{x 2 r e v} \varphi_{r e v}+K_{x 2 i n} \varphi_{i n}+K_{x 2 x 1} x_{1}+K_{x 2 y 1} y_{1}=0 \\
& M_{2} \ddot{y}_{2}+K_{y 21} \varphi_{1}+\sum_{i=5}^{6} K_{y 2 i} \varphi_{i}+K_{y 2 r e v} \varphi_{r e v}+K_{y 2 i n} \varphi_{i n}+K_{y 2 x 1} x_{1}+K_{y 2 y 1} y_{1}=0
\end{aligned}
$$

The solution of the eigenvalue problem determines the natural frequencies and normal modes of the system, which are shown graphically in figure 6. As it can be seen from Eq. (19), the lower the hydrodynamic film thickness, the higher the natural frequency of the corresponding gear pair with the film stiffness being proportional to $1 / h^{2}$. The natural frequencies of the shafts' rectilinear motions clearly dominate the corresponding FFT spectra, as it can be seen from the graphs of figure 6. The normal modes also reveal strong 
coupling between the motions of the $1^{\text {st }}, 4^{\text {th }}$ and reverse gears and between the motions of the $5^{\text {th }}$ gear and second output shaft in the $y$ direction, whilst a weaker form of coupling exists between the $3^{\text {rd }}$ and $6^{\text {th }}$ idle gears.

Wavelets of experimental measurements from the vehicle for similar temperature conditions, as in the numerical model are shown in the graphs of figure 7. The measurements were taking from the transmission housing pick-up points close to the input and output shaft bearing locations. The main frequencies observed in the spectra are explained as follows:

- $377 \mathrm{~Hz}$ corresponds to the natural frequency of the $3^{\text {rd }}$ gear pair $(367 \mathrm{~Hz})$, as well as to the meshing frequency of the same gear pair $(384 \mathrm{~Hz})$. In Table 1, the meshing frequencies of the gear pairs are provided (calculated by multiplying the number of gear teeth by the rotational speed of the corresponding gear). The frequency of $738 \mathrm{~Hz}$ is the 2nd order of the aforementioned frequency.

- $437 \mathrm{~Hz}$ corresponds to the natural frequency of the $6^{\text {th }}$ gear pair $(436 \mathrm{~Hz})$ and to the meshing frequency of the $5^{\text {th }}$ gear pair $(468 \mathrm{~Hz}$ ) (within $10 \%$ difference).

- $1760 \mathrm{~Hz}$ corresponds to the natural frequency of the $1^{\text {st }}$ output shaft $x$ and $y$ motions (1775 Hz and $1800 \mathrm{~Hz}$, respectively) with less than 3\% difference in both cases. It is also very close to one of the main natural frequencies of the transmission case (1750 $\mathrm{Hz}$ ), as it has been identified experimentally with hammer testing. In Table 2, the natural frequencies of the transmission housing below $3000 \mathrm{~Hz}$ are shown.

- $2001 \mathrm{~Hz}$ corresponds to the natural frequency of the $2^{\text {nd }}$ output shaft $x$ motion (1989 $\mathrm{Hz}$ ), whilst $2121 \mathrm{~Hz}$ and $2180 \mathrm{~Hz}$ correspond to the natural frequency of its $y$ motion (2146 Hz) with less than $2 \%$ difference in both cases. 
The above observations reveal a good agreement between the numerical analysis and the experimental findings. At this point, it is important to underline that the equation of motion of the input shaft has not been considered in the nonlinear analysis, since the kinematics of the shaft were available from experimental measurements for direct use, as input conditions in the numerical model. This arrangement has resulted in isolating the input shaft from accepting reactions backwards from the idle gears, which could be the case for the real system. However, these reaction forces are expected to have little effect on the dynamics of the system, since they are very low compared to the engine excitation. Nevertheless, the numerical analysis has predicted the vibration frequencies of both output shafts and the natural frequencies of the idle gear pairs, which are present in the spectra of the experimental measurements.

\section{CONCLUSIONS}

A new methodology for the study of idle gear rattle in automotive manual transmissions has been proposed, taking into account the effect of lubricated contacts. The lubricant behaves like a non-linear spring damper, affecting the response of idle gears during the meshing cycle. The examination of the linearised system has revealed its natural frequencies, demonstrating that lubricant viscosity is an important factor, which governs the overall system behaviour, affecting the interacting reaction forces, drag torque and friction in the gear pairs. The experimental measurements taken from a vehicle equipped with the same transmission type as the one modelled are in good agreement with the numerical findings. The inclusion of the transmission case (using FEA techniques) and the input shaft in the numerical model could be the following steps in this investigation, in 
order to shed more lights in the effect of those components on the overall system behaviour.

\section{ACKNOWLEDGEMENTS}

The authors wish to express their gratitude to Ford Motor Company and the EPSRC for the sponsorship and financial support extended to this research project. 


\section{REFERENCES}

[1] S. N. Dogan, G. Lechner, Maßnahmen zur Verringerung von Losteilschwingungen in Fahrzeuggetrieben, ATZ Autombiltechnische Zeitschrift 100 (1998) 10, pp. 710-716.

[2] S. Shih, J. Yruma, and P. Kittredge, Drivetrain Noise and Vibration Troubleshooting, SAE Technical Paper 2001-01-2809 (2001).

[3] R. Seaman, C. Johnson, and R. Hamilton, Component Inertial Effects on Transmission Design, SAE Technical Paper 841686 (1984), pp. 6.990-6.1008.

[4] C. Padmanabhan, T. Rook, and R. Singh, Modelling of Automobile Gear Rattle Phenomenon: State of the Art, SAE Technical Paper 951316 (1995).

[5] T. Fujimoto, and T. Kizuka, An Improvement of the Prediction Method of the Idling Rattle in Manual Transmission- In the Case of the Manual Transmission with Backlash Eliminator-, SAE Technical Paper 2001-01-1164 (2001).

[6] T. Sakai, Y. Doi, K. Yamamoto, T. Ogasawara, M. Narita, Theoretical and Experimental Analysis of Rattling Noise of Automotive Gearbox, SAE Technical Paper 810773 (1981), pp. 1-10.

[7] M. Wang, R. Manoj, and W. Zhao, Gear Rattle Modelling and Analysis for Automotive Manual Transmissions, Proc. Instn. Mech. Engrs. Vol. 215 Part D (2001), pp. 241-258.

[8] R. Singh, H. Xie, and R. Comparin, Analysis of Automotive Neutral Gear Rattle, Journal of Sound and Vibration (1989), pp. 177-196.

[9] T.C. Kim, R. Singh, Dynamic Interactions between Loaded and Unloaded Gear Pairs under Rattle Conditions, SAE Technical Paper 2001-01-1553 (2001), pp.1934-1943. 
[10] M. Kamo, H. Yamamoto, H. Koga, and K. Umezawa, Analysis Method for the Contribution Rate of Each Pair of Gears on the Driveline Gear Rattle, SAE Technical Paper 960726 (1996), pp. 221-227.

[11] M. Wang, W. Zhao, and R. Manoj, Numerical Modelling and Analysis of Automotive Transmission Rattle, Journal of Vibration and Control 8 (2002), pp. 921-943.

[12] R. Yakoub, M. Corrado, A. Forcelli, T. Pappalardo, and S. Dutre, Prediction of System-Level Gear Rattle Using Multibody and Vibro-Acoustic Techniques, SAE Technical Paper 2004-32-0063/20044350, 2004.

[13] A. Kahraman and R. Singh, Interactions Between Time-Varying Mesh Stiffness and Clearance Non-Linearities in a Geared System, Journal of Sound and Vibration (1991) 146(1), pp 135-156.

[14] G. Blankenship and R. Singh, A New Gear Mesh Interface Dynamic Model to Predict Multi-Dimensional Force Coupling and Excitation, Mech. Mach. Theory (1995) vol. 30 No. 1, pp. 43-57.

[15] S. Theodossiades and S. Natsiavas, Non-Linear Dynamics of Gear-Pair Systems with Periodic Stiffness and Backlash, Journal of Sound and Vibration (2000), 229(2), pp. 287310.

[16] S. Theodossiades and S. Natsiavas, On Geared Rotordynamic Systems with Oil Journal Bearings, Journal of Sound and Vibration (2001), 243(4), pp. 721-745.

[17] P. Bellomo, F. Cricenti, N. De Vito, C. Lang, and D. Minervini, Innovative Vehicle Powertrain Systems Engineering: Beating the Noisy Offenders in Vehicle Transmissions, SAE Technical Paper 2000-01-0033 (2000). 
[18] R. Brancati, E. Rocca, and R. Russo, A Gear Rattle Model Accounting for Oil Squeeze Between the Meshing Gear Teeth, Proc. IMechE Vol. 219 Part D: J. Automobile Engineering (2005), pp. 1075-1083.

[19] K. Umezawa, T. Suzuki, and T. Sato, Vibration of Power Transmission Helical Gears (Approximate Equation of Tooth Stiffness), Bulletin of JSME (1986), Vol. 29, No. 251, pp. 1605-1611.

[20] Y. Cai, Simulation on the Rotational Vibration of Helical Gears in Consideration of the Tooth Separation Phenomenon (a New Stiffness Function of Helical Involute Tooth Pair), Transactions of the ASME, Journal of Mechanical Design (1995), Vol. 117, pp. 460469.

[21] A. Rust, F. Brandl, and G. Thien, Investigations into Gear Rattle Phenomena - Key Parameters and their Influence on Gearbox Noise, IMechE, C404/001 (1990), pp. 113-120. [22] S. Doğan, Zur Minimierung der Losteilgeräusche von Fahrzeuggetrieben, Berichte Nr. 91 (2001), Institut für Maschinenelemente, Universität Stuttgart.

[23] M. Gnanakumarr, S. Theodossiades, and H. Rahnejat, The Tribo-Contact Dynamics Phenomenon in Torsional Impact Of Loose Gears - Promoting Gear Rattle, SAE 02ATT138, Society of Automotive Engineers (SAE)-ATT Congress, Paris, 2002.

[24] H. Rahnejat, The Influence of Vibration on the Oil film in Elasto-hydrodynamic Contacts, PhD Thesis, Imperial College, University of London, 1984.

[25] S. Theodossiades, O. Tangasawi and H. Rahnejat, Gear Teeth Impacts in Hydrodynamic Conjunctions promoting Idle Gear Rattle, submitted to the Journal of Sound and Vibration. 
[26] T. Sasaki, H. Mori and N. Okino, Fluid Lubrication Theory of Roller Bearings, Trans. ASME, J. Basic Engineering, 1962.

[27] R. Gohar, Elastohydrodynamics, Imperial College Press, 2001, $2^{\text {nd }}$ edition.

[28] T. Harris, Rolling Bearing Analysis, John Wiley \& Sons, Inc., $4^{\text {th }}$ Edition (2001).

[29] S. Timoshenko, D. H. Young, and W. Weaver Jr., Vibration problems in Engineering, John Wiley \& Sons, $4^{\text {th }}$ Edition, 1974. 


\section{FIGURE CAPTIONS}

Figure 1: Front Wheel Drive Transmission Layout

Figure 2: Contact Lines and Hydrodynamic Friction on Tooth Flank

Figure 3: Hydrodynamic Reaction and Petrov's Force

Figure 4: Accelerometer pick-up locations on the Transmission Housing

Figure 5: FFT Spectra of the output shafts' lateral responses (a) $x_{1}$, (b) $y_{1}$, (c) $x_{2}$ and (d) $y_{2}$

Figure 6: Natural Frequencies and Mode Shapes of the Linearised System.

Figure 7: Wavelets of the gearbox wall response close to the output and input shaft bearing locations 


\begin{tabular}{|c|c|c|c|c|c|c|}
\hline $1^{\text {st }}$ & $2^{\text {nd }}$ & $3^{\text {rd }}$ & $4^{\text {th }}$ & $5^{\text {th }}$ & $6^{\text {th }}$ & Reverse \\
\hline $172 \mathrm{~Hz}$ & $291 \mathrm{~Hz}$ & $384 \mathrm{~Hz}$ & $504 \mathrm{~Hz}$ & $464 \mathrm{~Hz}$ & $504 \mathrm{~Hz}$ & $107 \mathrm{~Hz}$ \\
\hline
\end{tabular}

Table 1: Meshing frequencies of the gear pairs

\begin{tabular}{|l|l|l|l|l|}
\hline $1020 \mathrm{~Hz}$ & $1200 \mathrm{~Hz}$ & $1430 \mathrm{~Hz}$ & $1750 \mathrm{~Hz}$ & $1845 \mathrm{~Hz}$ \\
\hline $2070 \mathrm{~Hz}$ & $2380 \mathrm{~Hz}$ & $2700 \mathrm{~Hz}$ & $2890 \mathrm{~Hz}$ & $3065 \mathrm{~Hz}$ \\
\hline
\end{tabular}

Table 2: Natural frequencies of the gearbox in the frequency region below $3000 \mathrm{~Hz}$ 


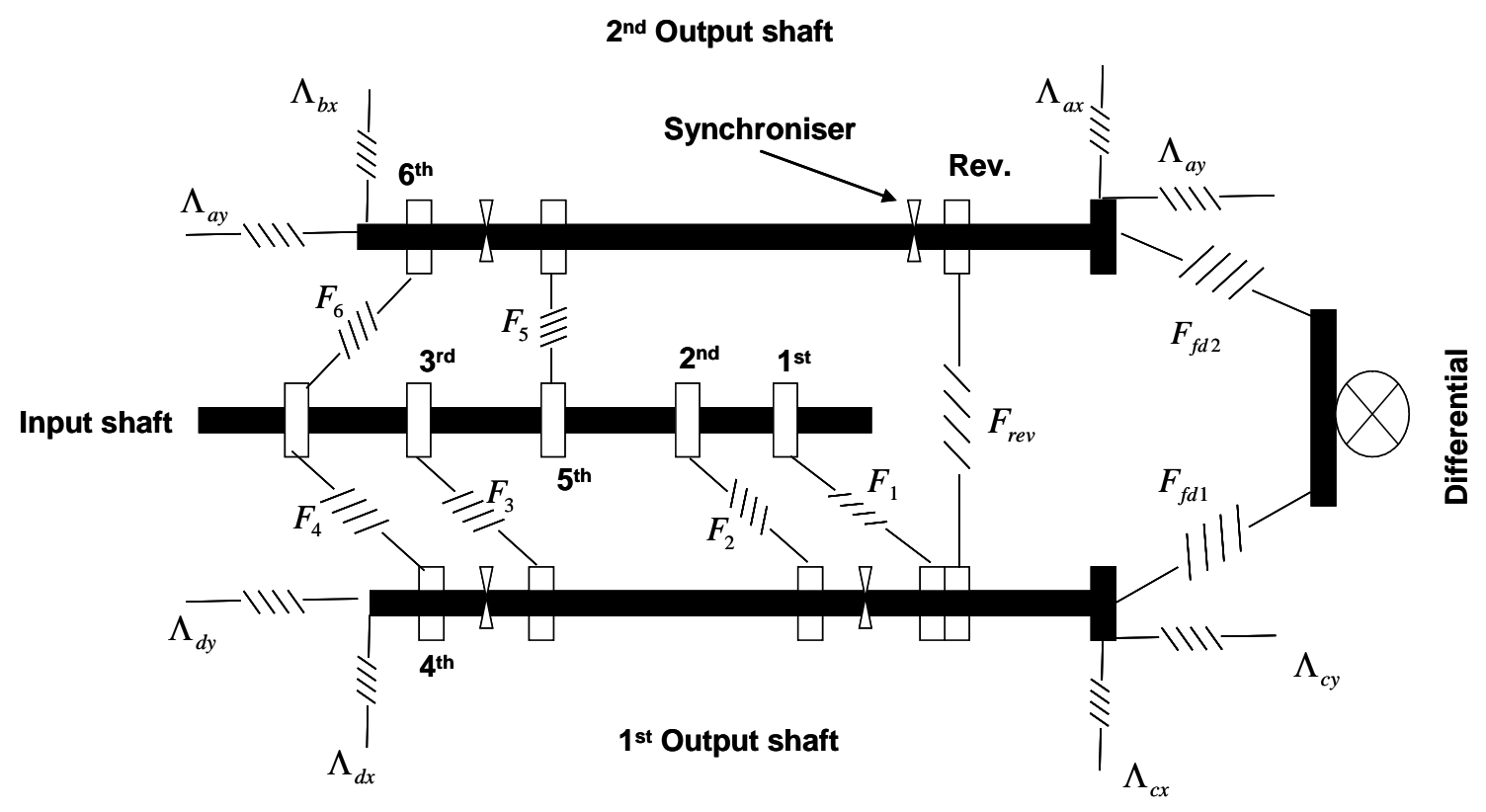

Figure 1: Front Wheel Drive Transmission Layout

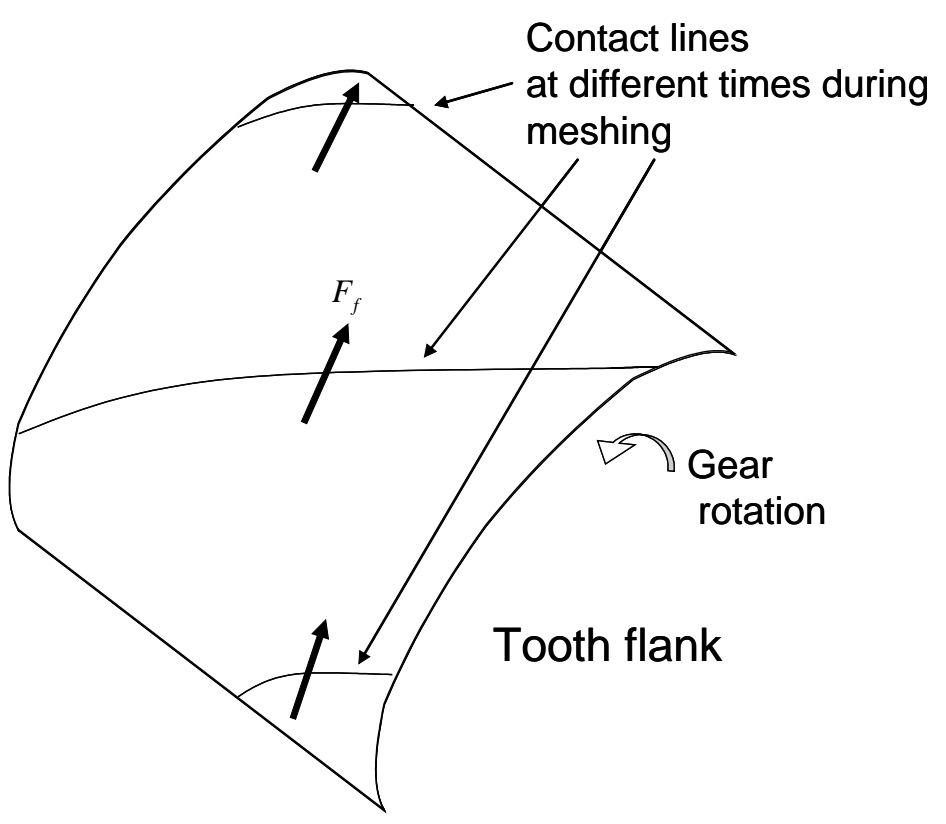

Figure 2: Contact Lines and Hydrodynamic Friction on Tooth Flank 


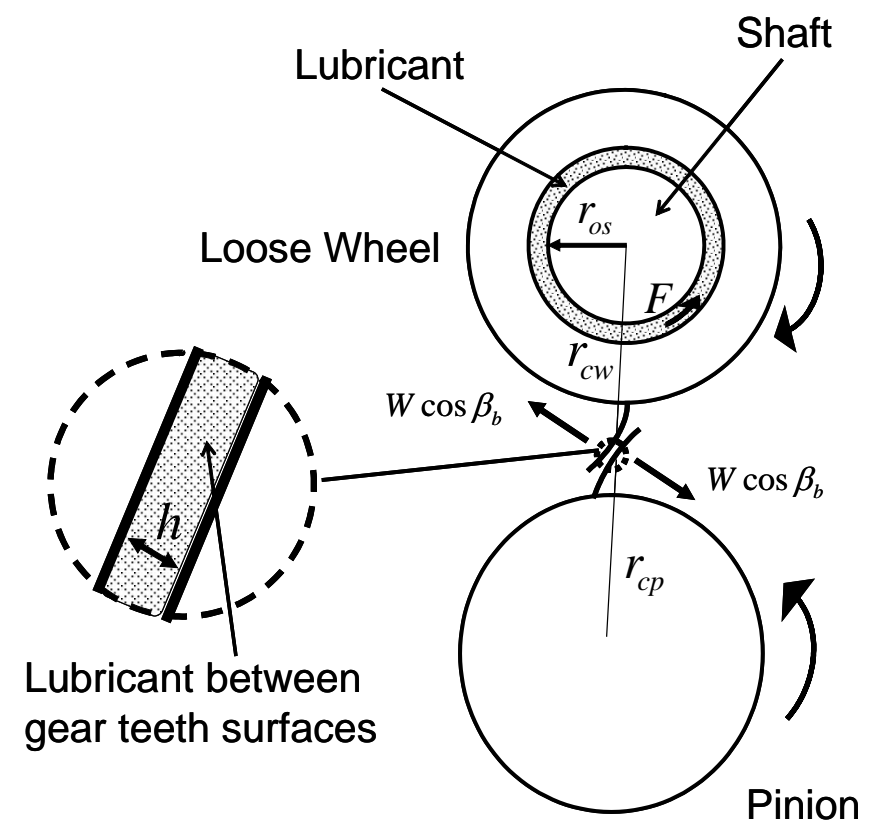

Figure 3: Hydrodynamic Reaction and Petrov’s Force
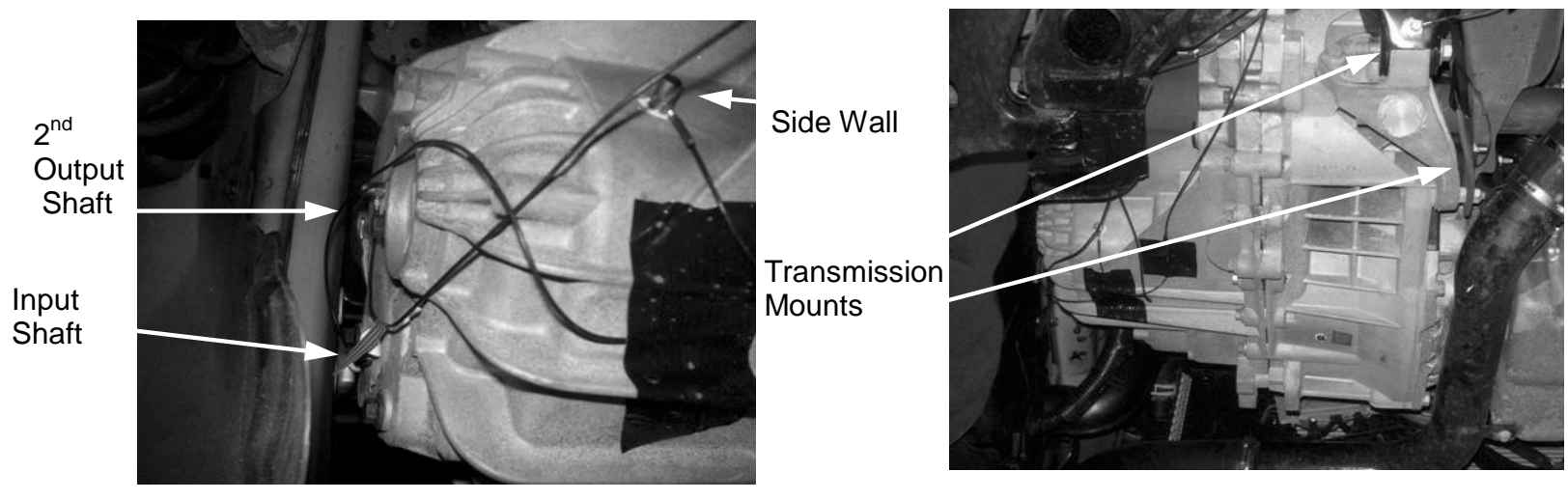

Figure 4: Accelerometer pick-up locations on the Transmission Housing 

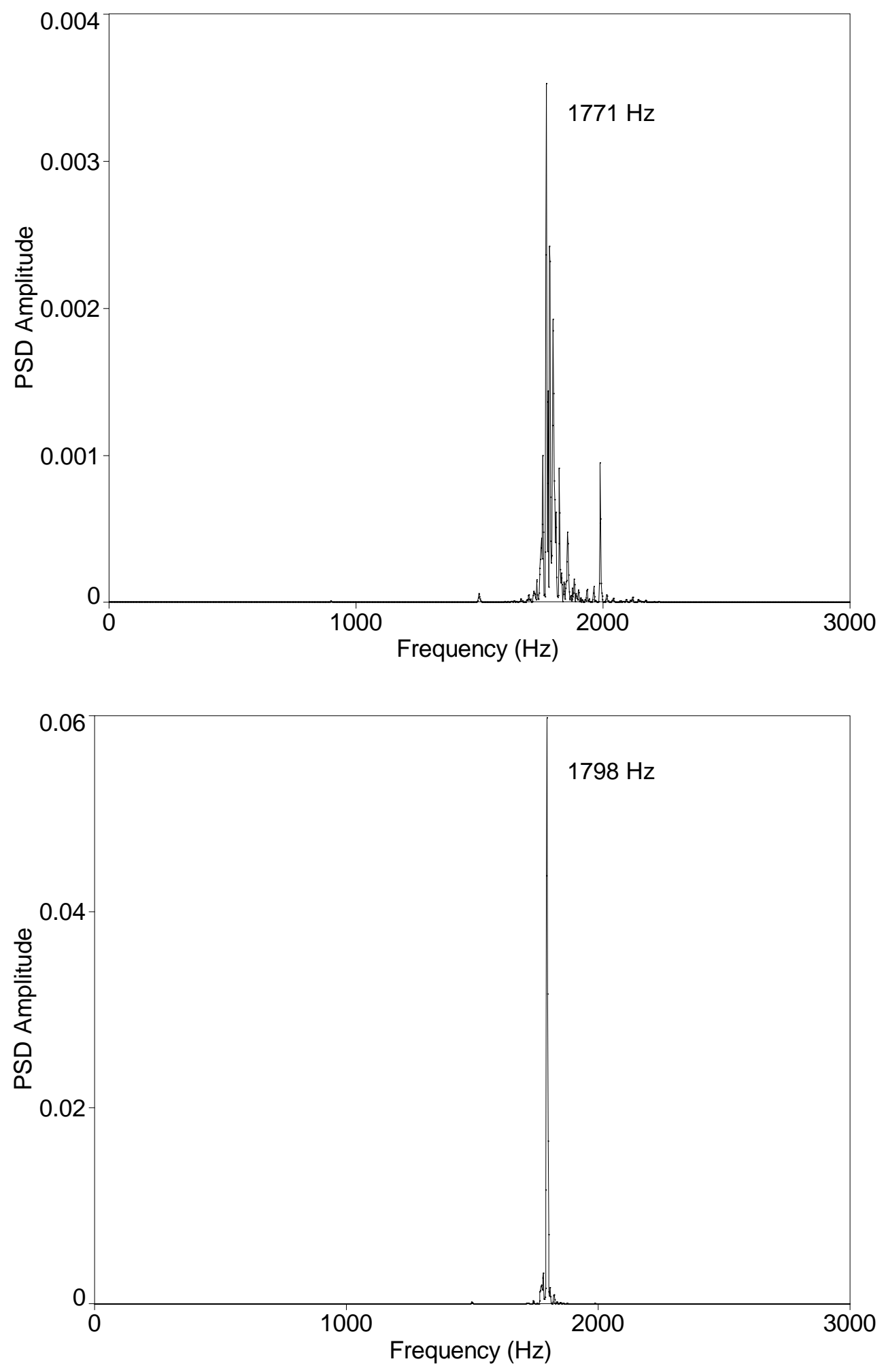

Figure 5 (continued over) 

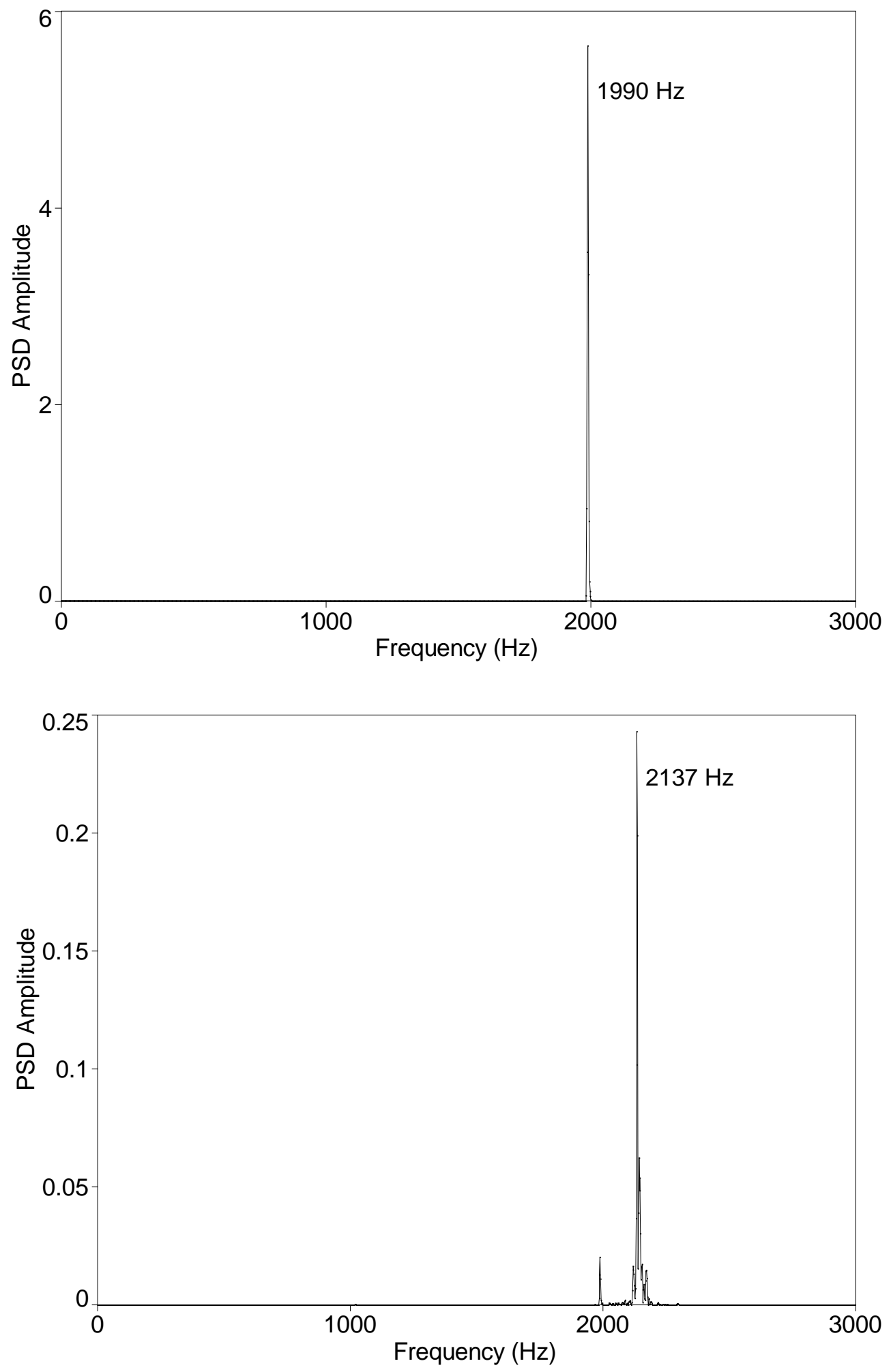

Figure 5: FFT Spectra of the output shafts' lateral responses

(a) $x_{1}$, (b) $y_{1}$, (c) $x_{2}$ and (d) $y_{2}$ 

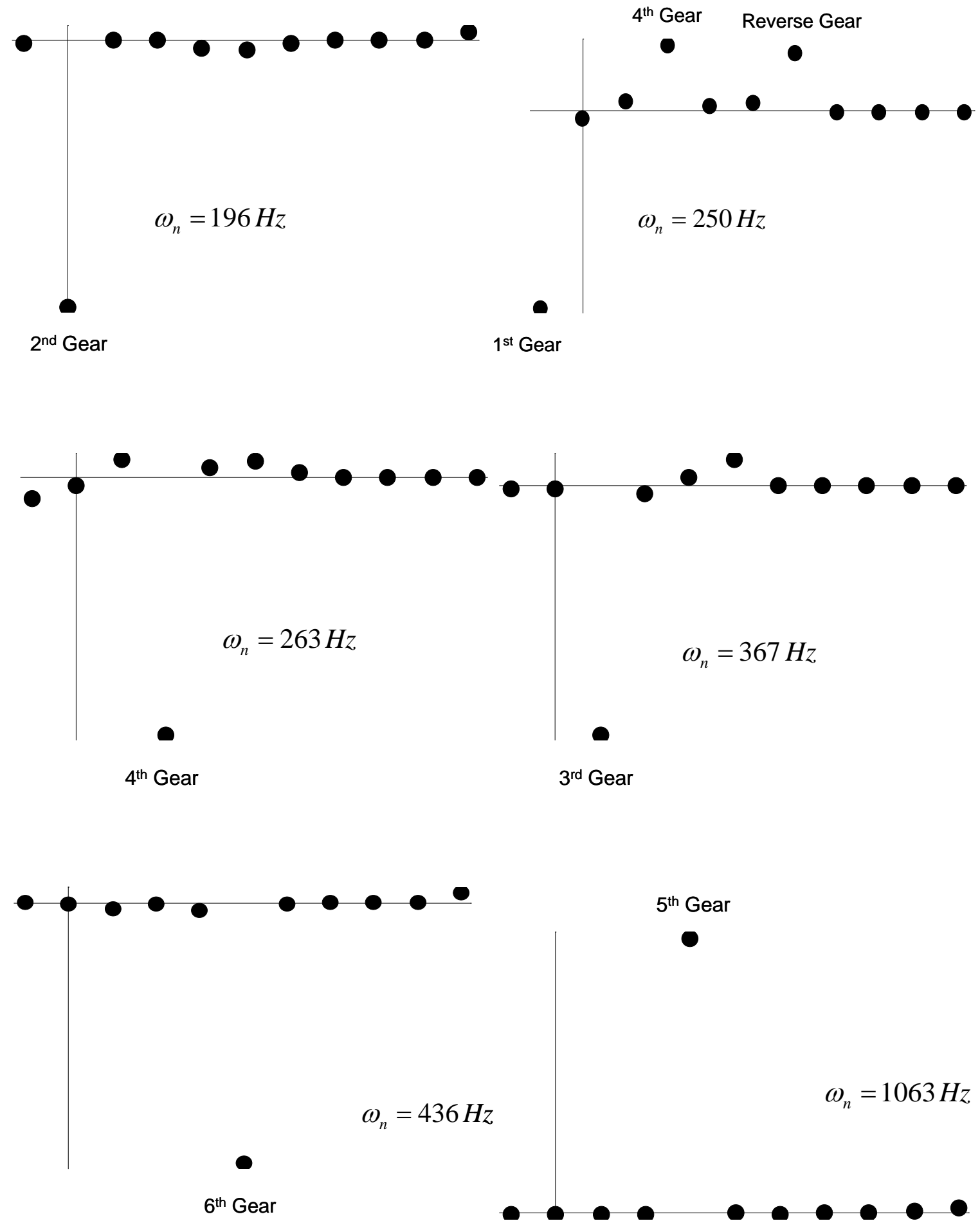

Figure 6 (continued over) 

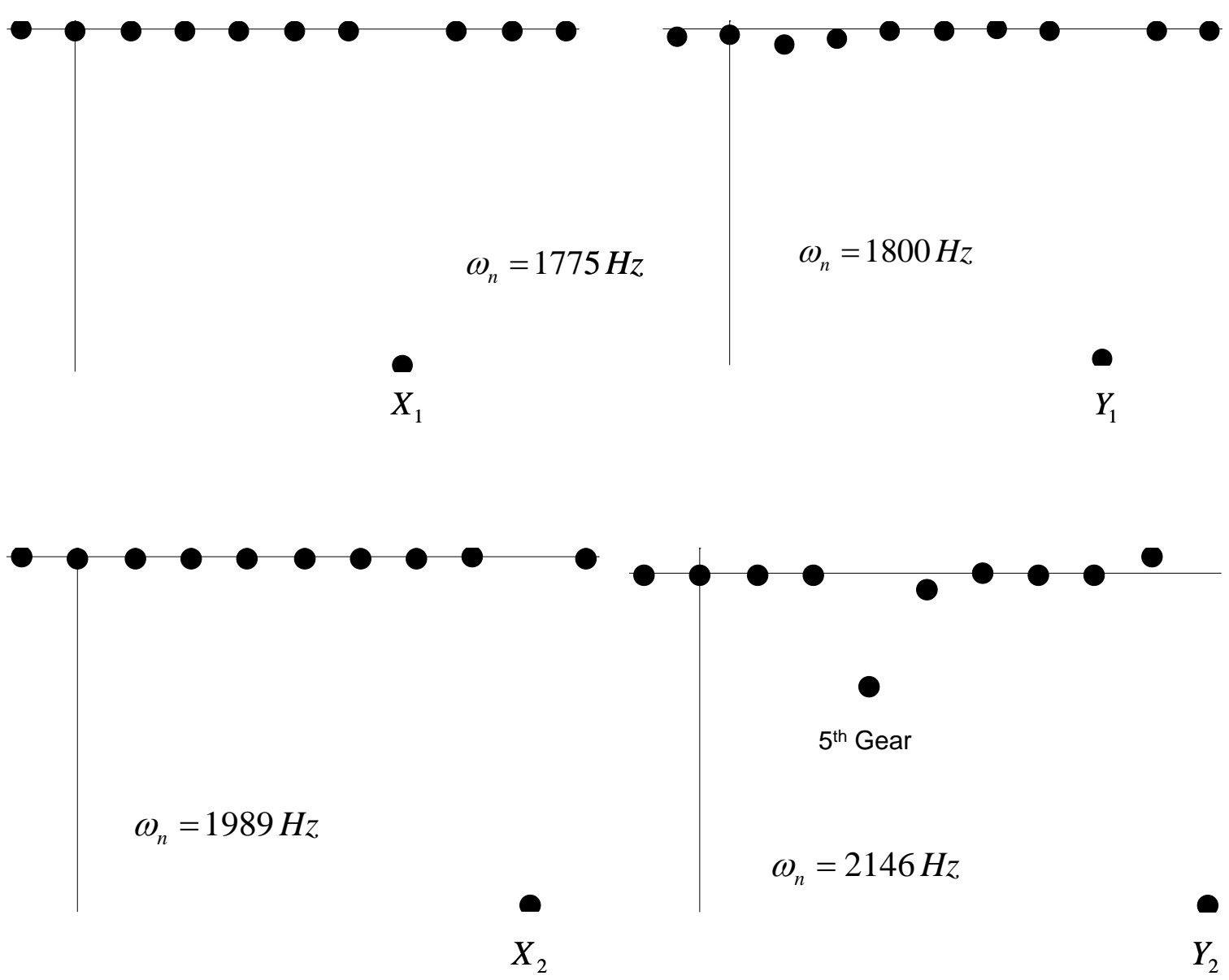

Figure 6: Natural Frequencies and Mode Shapes of the Linearised System 

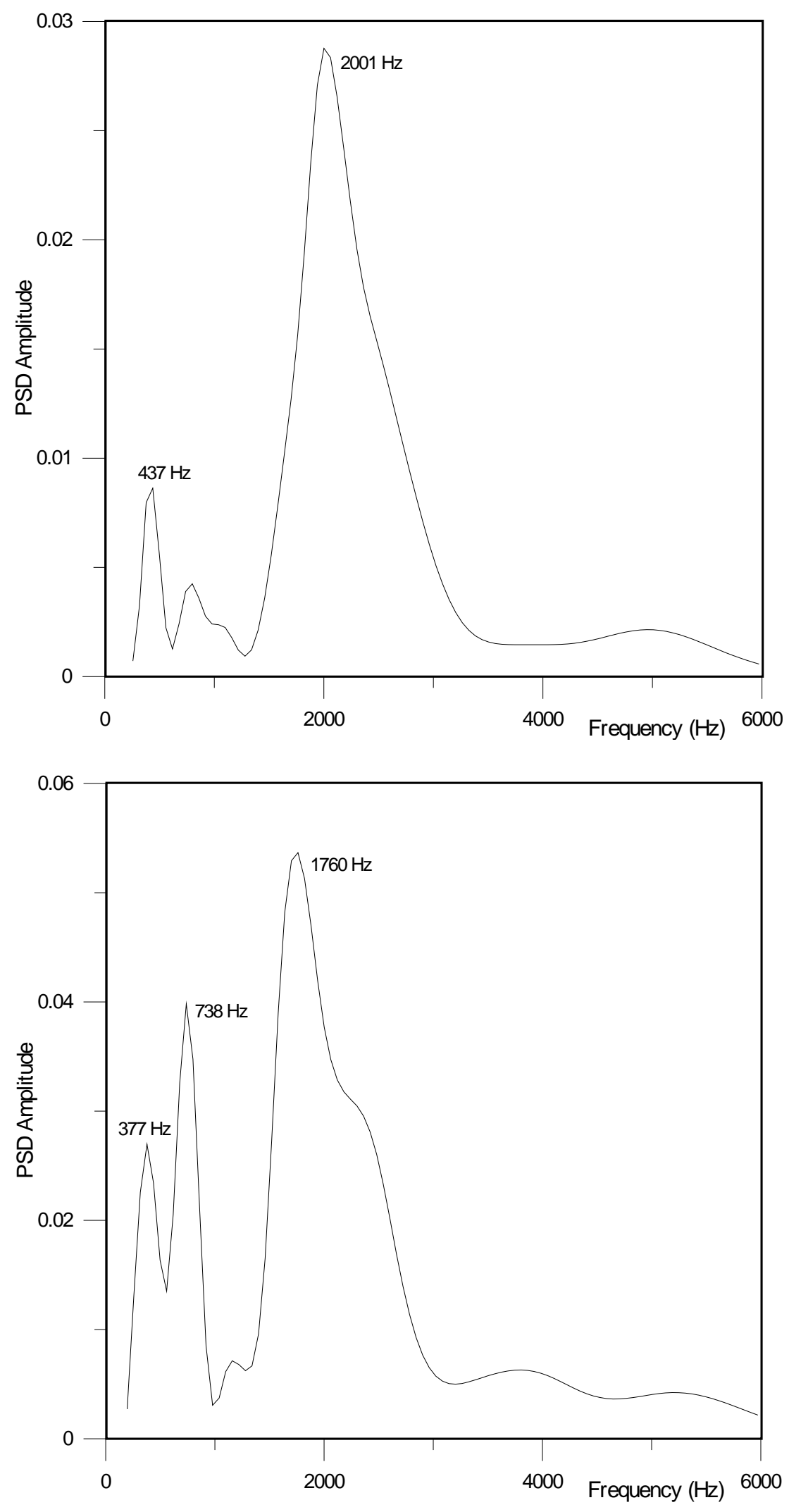

Figure 7 (continued over) 

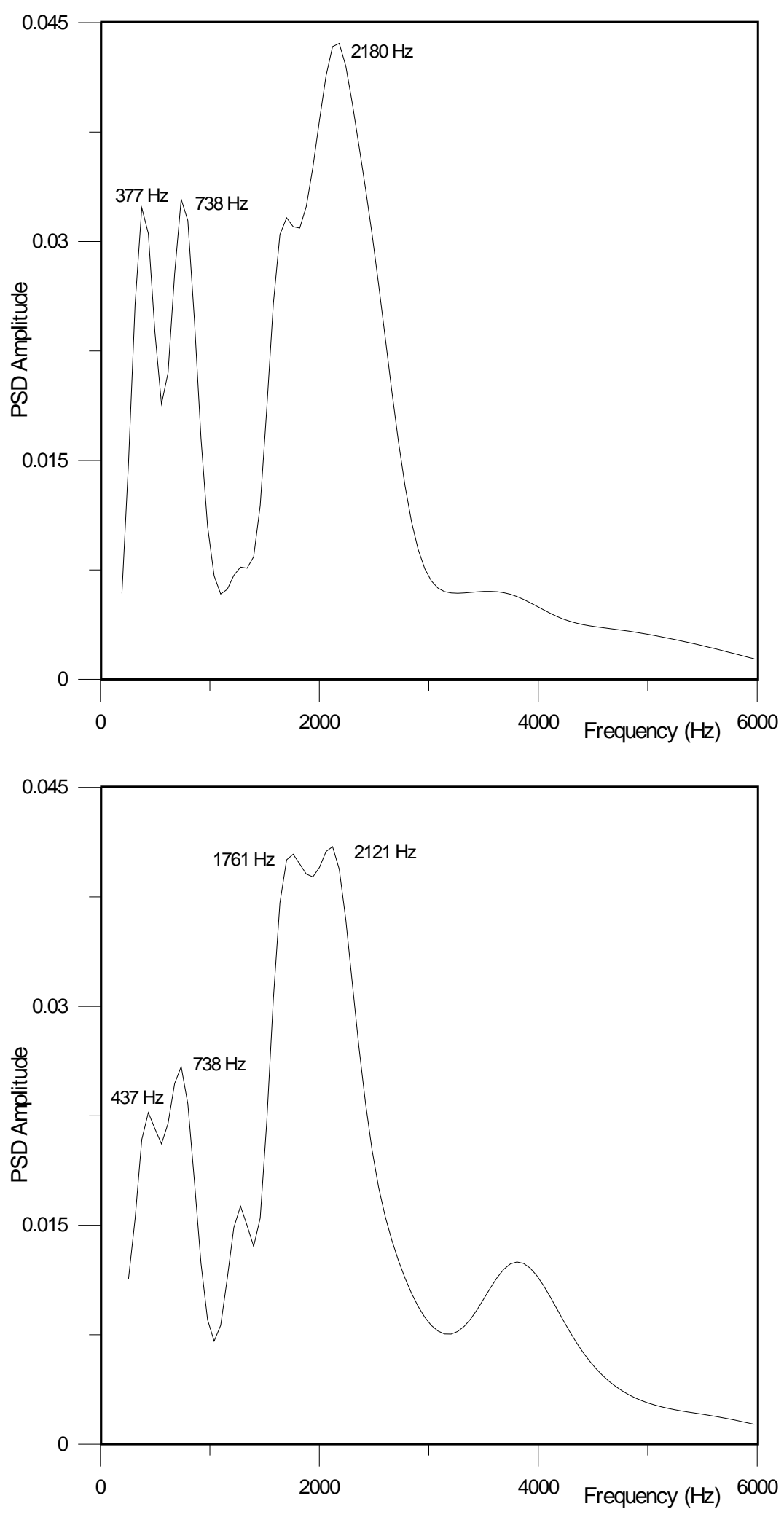

Figure 7: Wavelets of the gearbox wall response close to the output and input shaft bearing locations 